\title{
The Political Economy of Adaptation through Crop Diversification in Malawi
}

\author{
Blessings Chinsinga, Ronald Mangani and Peter Mvula*
}

Abstract This article demonstrates the politics of the policy processes of adaptation using the case of crop diversification. Competing narratives among different actors illustrate the complexity of practically translating crop diversification in practice. The context in which policy processes take place matter a great deal since adaptation policies' chance of success cannot be judged abstractly in their theoretical or technical attributes without considering the institutional, political and cultural context in which they are applied. This draws attention to the fact that policy processes are less of a linear sequence but more of a political process, underpinned by a complex mesh of interactions and ramifications between a wide range of stakeholders who are driven and constrained by the competing interests and contexts in which they operate.

\begin{abstract}
1 Introduction
A recent World Bank report (2010) considers Malawi as one of the 12 most vulnerable countries to the adverse effects of climate change in the world. Malawi's vulnerability is particularly heightened by its excessive dependency on rain-fed agriculture. As high as 85 per cent of Malawians eke their livelihoods directly out of agriculture, which contributes over 90 per cent to the country's export earnings, about 39 per cent of the country's gross domestic product (GDP) and accounts for about 85 per cent of total employment (Chinsinga 2008). This was further underscored by the 2005 Integrated Household Survey (IHS), which showed that five out of the eight most serious shocks that households grapple with are agricultural in nature (Makoka 2008). These shocks, in order of severity, include large rises in food prices, lower crop yield due to drought or floods, large falls in crop sales, death or theft of livestock and crop diseases or pests.
\end{abstract}

The seriousness of the problem of climate change and its negative effects on livelihoods of the people is widely recognised in Malawi, even though no single coherent policy framework exists. There are nonetheless several sector policies such as crop production (1990); national environmental management plan (1994); national forest (1996); national irrigation (2000); national water (2004); and national land resources management (2005), among many others, that are related to addressing various adverse effects of climate change. In addition to the sectoral policies, Malawi developed and adopted the National Adaptation Programme of Action (NAPA) in 2006 which, at least on paper, serves as a framework for climate change adaptation efforts in the country. The objectives of the NAPA are to improve community resilience, restore forests, improve agricultural production, and improve preparedness for floods and droughts.

This article examines the opportunities and challenges of climate change adaptation in Malawi using the case of crop diversification. It draws from an innovative experiment about policy engagement and influence between two sets of researchers: those working with the Research to Policy for Adaptation project and Participatory Action Researchers within the framework of the Climate Change Adaptation in Africa (CCAA) programme, an IDRC and DFIDfunded project called Strengthening Agricultural Systems in Tanzania and Malawi to Adapt to the Challenges and Opportunities Arising from Climate Change and Variability. The main 
argument of the article is that success in policy engagement and influence is dependent on several interacting and often highly dynamic variables which require researchers to be familiar with the policy processes perspective instead of treating policymaking as essentially a technocratic endeavour. This draws attention to the fact that policy processes are less of a linear sequence but more of a political process underpinned by a complex mesh of interactions and ramifications between a wide range of stakeholders who are driven and constrained by competing interests and contexts in which they operate. The main message is that the context in which policy processes take place matters a great deal, since adaptation policies' chance of success cannot be judged abstractly in their theoretical or technical attributes without considering the institutional, political and cultural context in which they are applied.

\section{Research, policy engagement and influence: the experiment}

As indicated above, this article draws from an innovative experiment about policy engagement and influence that brought together two sets of researchers: those with the Research to Policy for Adaptation project and Participatory Action Researchers in the CCAA programme. The former are mainly experts in policy processes, whereas the latter are experts in climate change adaptation. The underlying goal of the policy engagement and influence experiment was to explore how outcomes from the scientific research on climate change adaptation can feed into the mainstream policy processes as well as influence and shape the final policy outcomes on adaptation.

The engagement between Research to Policy for Adaptation and Participatory Action Researchers was guided by the conceptual framework for policy processes developed in the Knowledge, Technology and Society (KNOTS) team at the Institute of Development Studies (IDS) (Keeley and Scoones 2003; IDS 2006). The framework analyses policy processes from three perspectives: narratives and evidence, actors and networks, and politics and interests. The basic thrust of the framework is the way in which policies are talked about, and the associated values, power relations and politics that frame policies in a particular way. This underlies the political economy approach to policy processes which is key to understanding processes that create, sustain and transform relationships among various segments of society over time. The significance of the political economy approach is that it helps to identify and understand the political, economic and social processes that promote or block propoor change as well as the role of institutions, power and the underlying context for policy processes (Synder 2005). This, inter alia, suggests that policies are more effective when they are informed by an understanding of power relations, incentives and change processes.

From a political economy vantage point, the policy processes approach offers an alternative to the technocratic perspective about policymaking. According to Araujo et al. (2004), the policy processes approach embraces steps of discussion, negotiation, approval and implementation, which are at the core of the 'messy' world of politics. This implies that policy processes can be adversarial, characterised by the clash of competing interests and viewpoints, rather than impartial, disinterested and objective search for correct solutions for policy. The KNOTS framework therefore draws attention to the fact that policymaking and processes cannot be reduced to universal recipes that are supposed to work irrespective of the time and place in which they are adopted.

The main goal of using the KNOTS framework was to identify existing as well as potential policy spaces that Participatory Action Researchers could exploit for policy engagement and influence. The idea was to use the Participatory Action Researchers' cumulative experience during the project to develop policy engagement strategies for use in subsequent policy engagement and influence efforts. This would draw from cumulative insights about what worked, what did not work and under what circumstances. Overall, the policy engagement strategies would provide broader pointers to a set of do's and don'ts for potentially effective policy engagement and influence efforts.

We chose a case study on crop diversification as a means of systematising the engagement between the Research to Policy for Adaptation and Participatory Action Researchers. It served as a lens for grasping and engaging with the policy processes of climate change adaptation in the country. The Participatory Action Researchers' 
project promotes adaptive strategies in both high and low potential areas by introducing communities to various mixes of adaptation strategies. The choice of the crop diversification study was based on two main drivers. First, crop diversification was widely identified by communities themselves as a priority adaptation strategy during the situation analysis, prior to the launch of the project (Joshua et al. 2008). Second, Malawi's famous input subsidy programme is touted as a mechanism for facilitating crop diversification. Donors pledged to support the input subsidy programme, entirely funded by the government during its first year of implementation, on condition that it would promote other crops besides maize (Chinsinga 2007).

The Research to Policy for Adaptation Researchers engaged with Participatory Action Researchers in a participatory manner to facilitate mutually beneficial mentorship and learning opportunities. The participatory mode of engagement was progressively built around a policy processes dialogue session that essentially kick-started the innovative experiment about policy engagement and influence. The dialogue session focused on the KNOTS conceptual framework specifically and the policy processes more generally. This offered the opportunity for the two sets of researchers to map out extensively the climate change and variability landscape in the country which helped to identify existing and potential policy spaces as well as brainstorming on how they could be exploited and additional ones created.

The policy processes dialogue session was then followed up by quarterly meetings, regular and ad hoc e-mail exchanges, sharing of key project reports, a series of field visits and learning events. The quarterly meetings were very important because they provided a useful forum to discuss the Participatory Action Researchers' experiences with policy engagement and influence efforts for the previous quarter. The meetings functioned as post-mortem and mentoring clinics, reviewing goals and targets set in the previous quarter and setting goals for the next quarter. These meetings generated lessons on what worked, what did not work and under what circumstances. This greatly helped to refine policy engagement and influence strategies going forward.

\section{Policy engagement and influence efforts: the results \\ 3.1 Narratives and counter narratives on crop diversification}

There is consensus that crop diversification is a desirable strategy for safeguarding rural livelihoods in the context of uncertain climates (cf. Makoka 2008). According to evidence from the Participatory Action Researchers' project (Joshua et al. 2010), crop diversification cushions farmers against the adverse effects of climate change through spreading risks, increasing the levels of income and improving the nutrition and health status of communities. Farmers emphasise mainly the potential of crop diversification to guarantee food availability in case of failure of other crops. District level NGO and government officials principally regard crop diversification as a means of boosting soil health and improving the incomes of the people. Donors project crop diversification primarily as a means of improving the nutritional status of a society deeply wedded to maize food products.

However, the discourse about crop diversification is not entirely new. The crop production policy promotes diversification of both food and cash crops as a strategy for import substitution or expanding exports while accommodating changing market conditions (GoM 1990). Until the prominence of climate change adaptation on the policy agenda, crop diversification was mainly viewed as a strategy for attaining food security as stipulated in the crop production policy. The rise of adaptation onto the policy agenda has triggered new layers of narratives or discourses about crop diversification as a strategy for climate change adaptation. In other words, the discourse about crop diversification has extended beyond food security to how it can or cannot serve as a sustainable adaptation strategy for addressing the adverse effects of climate, as demonstrated below.

The narrative of crop diversification as an adaptation strategy is challenged by the political imperative to ensure food security, which is equated with having enough maize at both national and household levels. Besides, there is a strong cultural orientation that equates food to maize at the community level. For instance, in some of the project sites, farmers confessed 'we do not divorce food from maize to the extent that we are reluctant to grow non-traditional crops for food which in 
our view is a great risk'; ' and 'maize is food and if we do not grow it, we fear we will not have food'. 'This cultural orientation is therefore further entrenched by the government's fixation on maize as a means for achieving and maintaining food security.

The input subsidy programme has failed to promote crop diversification even though it was designed as such. The alternative cereals and legumes are almost always unavailable at the designated selling points (Dorward and Chirwa 2009). In many ways, this is a culmination of the coincidence of interests among government, donors and seed companies. While constantly making references to the ideals of crop diversification, the main preoccupation of the government is to achieve food security because of its centrality in the country's electoral politics. ${ }^{3}$ For the government, food security can be guaranteed by the use of high-yielding hybrid maize varieties. Seed companies are keen to promote hybrid maize seeds since they are their main product and through the subsidy programme, seed companies are guaranteed a ready market. Donors are interested in promoting a private sector-driven input supply system through the promotion of agro-dealers to fill the vacuum following the dismantling of the state-driven input supply system through liberalisation. This has made hybrid maize the dominant seed that is made available to farmers through the input subsidy programme.

Most communities argue that crop diversification cannot be a success due to the cultural orientation that equates food to maize. Foodstuffs made from alternative cereals such as millet and sorghum are widely perceived as 'inferior', to the extent that households resorting to such foodstuffs are taken to be desperate. Consequently, households desist from using alternative cereals because they would not want to project themselves as desperate to the rest of the community. This undermines the drive towards crop diversification, which is further reinforced by severe land constraints, labour intensity, limited productivity and lack of lucrative markets for alternatives to maize (Smale and Jayne 2003). It is estimated that about 49 per cent of smallholder farmers do not own more than a hectare of land.

For most international humanitarian NGOs, crop diversification is desirable but not attainable as long as weather index insurance schemes are exploited as commercial ventures by the private sector. They condemn the insurance schemes as a barrier to crop diversification mainly due to their institutional arrangements. Farmers take loans from a designated bank; procure seeds from a specified company; and dispose of their produce to a designated buyer. Not only are the farmers bound up in a particular institutional arrangement that effectively curtails their freedom but the seed companies involved are known to promote almost exclusively hybrid maize. The institutional arrangement is further deemed exploitative because premiums are as high as 10 per cent of farmers' expected income. This is higher than the market rate that averages around 7 per cent.

There are some communities who contend that crop diversification is actually a narrower concept. They argue that there is a need to promote livelihood diversification as climatic patterns become more and more uncertain. This narrative appears to have been inspired by unique local-level politics in these communities which, in their view, makes livelihood diversification more appropriate than just crop diversification. The local-level politics present barriers to crop diversification because of competing interests between farmers on one hand and other stakeholders on the other. The argument is that livelihood diversification would make farmers 'immune or insulated from the vagaries of erratic climatic patterns especially when there are strategic barriers to crop diversification'. ${ }^{4}$

For example, farmers cannot get the water they require for irrigation which is the main means for cultivation in one of the project sites. A sugar company in their neighbourhood deliberately blocks water to the farmers' fields at critical periods of crop development. The company argues that it has to control the water levels if sugar production is to meet internationally acceptable quality standards, while communities view the company's act as 'a deliberate strategy to guarantee itself a readily available pool of cheap labour which would otherwise be difficult if we [farmers] were to become economically independent ${ }^{5}{ }^{5}$ It would thus not be attractive for the farmers to work as casual labourers on the company's sugar plantations.

In another site, farmers have lost access to a lucrative market for pineapples which greatly 
fostered crop, if not livelihood diversification. Farmers used to sell pineapples to a canning factory that is in their neighbourhood. However, the factory discontinued buying pineapples directly from farmers. Instead, the factory buys pineapples from vendors, the justification being that the quality of pineapples from the farmers was low. According to the farmers, the factory's justification is not credible at all since the vendors buy the pineapples from the same farmers at lower prices which they then sell to the canning factory at higher prices. The factory workers have simply captured the market for themselves using vendors as a front for what is essentially insider trading.

\subsection{Policy spaces, engagement and influence}

The main policy space has been the National Consultative Group (NGG). The NGG brings together influential policymakers from different sectors working on issues of climate change adaptation. It draws membership from civil society organisations, government departments and ministries, donor agencies and the media.

The idea to constitute an NCG followed an extensive mapping of the climate change adaptation policy terrain in the country with the aid of the KNOTS framework. The exercise helped to identify key actors in various sectors such as civil society, government, media and donor agencies. The initial members of the NCG were identified by the project team who were then briefed about their potential role at its inaugural meeting. They were, however, given the opportunity to develop their own terms of reference and assess the adequacy of the membership. The membership of the NCG has essentially remained the same but from time to time, other relevant stakeholders have been invited to 'witness' on specific issues depending on the breadth and depth of their skills and expertise. The NCG is chaired by the Chairperson of the Parliamentary Committee on Agriculture and Natural Resources which has somewhat accorded it the requisite political profile.

The NCG has been fairly instrumental in debating some key issues relating to crop diversification and climate change adaptation. The results of the Participatory Action Researchers have triggered debate about the appropriate timing of the subsidy programme in the low potential areas. The key question the NCG has engaged with is whether it makes sense to distribute subsidised inputs in summer when the rains are increasingly becoming unreliable. The evidence from the research has swayed the NCG to recommend to government to consider switching the provision of subsidy inputs to farmers from summer to winter, since farmers simply sell the inputs or reserve them for winter cultivation. This debate opened up opportunities for linking up disadvantaged communities in the project sites with the Ministry of Irrigation and Water Development. And through this NCG debate, several communities have acquired irrigation facilities that have enhanced crop diversification and the resilience of their respective communities to adapt to the adverse effects of climate change.

In a learning event that brought together stakeholders from all project sites including the NGG members, testimonies of communities engendered debate about the conduct of seed companies. The farmer representatives argued that seed companies are contributing to the failure of communities to adapt to the adverse effects of climate change because 'they are primarily motivated to maximise as much profit as possible at the total neglect of farmers' welfare' ${ }^{6}$ The concern of farmers is that seed companies no longer distribute seeds according to the agroecological zones of the country. The NCG engaged with the Seed Traders Association of Malawi (STAM) and the government to ensure that seeds are distributed according to their agro-ecological appropriateness and relevance through the input subsidy programme which guarantees a market for their seed products.

The role of the media has been quite important in raising the profile of the project. The inclusion of the media in the NGG has helped to popularise the project in the policymaking circles beyond the NCG membership. The high media profile, propelled in part by primary accounts of communities' experiences across the project sites, has been very effective in bringing the results of the project onto the radar screen of policymakers. This is, for instance, underlined by the fact that the Participatory Action

Researchers were requested to input into a presidential speech that was delivered at the G8 summit in Canada in June 2010 in his capacity as the Chairperson of the African Union, as well as in his engagement with the UN Secretary General when he visited Malawi in July 2010. 
While the NCG has functioned as a creative tool for policy engagement and influence, it has not been without its own challenges. There is no doubt that the NCG provides a fairly relaxed informal atmosphere for stakeholders coming from, and subscribing to, widely different worldviews about climate change adaptation to build some consensus towards a shared vision about the nature of the problem, what needs to be done to deal with it and the likely consequences if the problem if left unattended to. However, discussions in the NCG are often charged because members are unable to completely shed off their institutional ideological convictions. A very good example is the great ideological divide between government agencies and civil society organisations. Overall, government agencies' strategies are hugely orientated toward mitigation, while civil society organisations promote almost exclusively, adaptation. As a result of the strong institutional identities, it is often difficult to reach consensus on issues as quickly as possible. It is, however, generally easier for NCG members to reach consensus in their own individual capacities and not on behalf of their institutions, which raises the critical question about how the KNOTS policy processes framework can address the question of the interface between formality and informality in policy engagement and influence.

\subsection{The KNOTS framework: adding value and lessons} The major strength of the KNOTS framework for policy processes is that it helps to understand the constraints and incentives that condition the actions of various actors in the policymaking exercises. The other strengths of the framework:

- It simplifies the notion of policy engagement and influence, especially when backed up by the outcome mapping journal.

- It provides a useful entry point for policy engagement and influence through systematic mapping of narratives, since they provide an understanding of the whole range of interests.

- It helps researchers to understand the policy architecture both generally and with specific reference to the sector of interest, which plays an important role in identifying existing and potential policy spaces.

- It relays the fact that policy processes are not simply technical fixes but rather heavily imbued political processes in which creating networks is just as important as generating new evidence.
- Researchers must at least demonstrate value addition to what policymakers already know, in order to capture their attention and excite interest for further engagement.

- Some measure of informality plays a key role in effective policy engagement and influence, since building trust with policymakers is vital, as demonstrated through the NCG.

- Policy engagement and influence are resource intensive exercises both in terms of time and finances, since success is greatly dependent on sustained efforts over a long period of time.

The main limitation working with the KNOTS framework is that it is difficult to capture the dynamism of the policy processes. The notion of policy spaces seem to suggest that once they have been identified and exploited, then that settles it once and for all, yet policy processes involve winners and losers who continue to engage using a variety of strategies building on their experiences with the initial policy processes. Thus, the identification of policy spaces does not necessarily imply the end of the policy processes. While winners strive to maintain the status quo, losers are determined to change the status quo (Leftwich 2007). It is also difficult to address the question of how scientific researchers can work on their own using the KNOTS policy processes framework.

While the goal of the project is to develop policy engagement strategies, it is difficult to see how scientific adaptation researchers can effectively work with the framework on their own. Yet, working with scientific researchers within the KNOTS framework is quite challenging. The experience in this project is that the scientific researchers develop a dependency attitude on the policy process researchers. This greatly undermines mentorship and capacity building, which invariably creates a situation in which policy process researchers become heavily involved as key actors instead of merely serving as facilitators. The challenge is that close involvement with scientific researchers in policy engagement and influence makes it difficult for policy process researchers to maintain the critical and analytical distance to further practical learning about policy engagement and influence.

\section{Conclusion}

The major lesson from the innovative policy engagement and influence experiment is that policy influence is not merely a question of 
generating robust scientific evidence and making it available to policymakers. It is as much generating new evidence as it is creating strategic partnerships, coalitions and alliances (Clayton and Gulshaw 2009). Policy engagement and influence entails engaging with policymakers for them to understand the implications of new or even old evidence as vital input into their decision-making processes. The manner therefore in which evidence is packaged, how it is communicated to policymakers, by whom and when matters a great deal for researchers to effectively engage with policy processes and influence the final outcomes. The main implication of the KNOTS framework is that processes of discussing, negotiating, approving and implementing policies are as important as the scientific content of the policies themselves.

The innovative experiment on policy engagement and influence has shed light on the political economy of crop diversification as an adaptation strategy to the adverse effects of climate change in Malawi. While there is consensus on the desirability of crop diversification as an adaptation strategy, the case study has shown that there are some serious constraints to translate it into practice. The smooth implementation of crop diversification as an adaptive strategy is constrained by competing interests of the key stakeholders who have different notions about how it can actually be done. The main obsession of the stakeholders is to promote, protect and safeguard their own selfish interests.

\section{Notes}

* Research for this article was conducted under the Research to Policy for Adaptation project, funded through the Climate Change Adaptation in Africa (CCAA) programme. CCAA is a joint programme of the International Development Research Centre (IDRC) and the UK's Department for International Development (DFID). The research also benefited significantly from the Climate Change Theme of the Future Agricultures Consortium (FAC), a DFIDfunded partnership of leading independent research institutes working on African agricultural policy. The views expressed here are the views of the authors and do not represent the views or policies of IDS, DFID, or IDRG.
The major contribution of this article is that it has demonstrated that what eventually gets done is dependent on how power relations, incentives and change processes play out among the key stakeholders. The experiences with crop diversification show that dominant stakeholders almost always have their way. The case study shows that the implementation of crop diversification has been constrained by a dominant narrative that equates food security with maize. The input subsidy programme, which is the single most important resource in the agricultural sector, has been captured by politicians primarily to advance their own political goals. Their primary focus is on achieving food security, construed as maize selfsufficiency at national and household levels, even though the input subsidy programme was designed to serve as a vehicle for crop diversification.

Alternative narratives have had no significant effect on the mainstream narrative of crop diversification that equates food security with availability of maize. In this regard, the case study sheds light on the dynamics of political, economic and social processes that either promote or block pro-poor change. In the broadest sense, therefore, the political economy approach to policy processes is vital to understanding the political, social and economic factors that shape development challenges and outcomes, in particular causes of poor governance and policy failure.

1 Focus Group Discussion with men farmers at Mnesa village in Mulanje district.

2 Focus Group Discussion with women farmers at Mpasu village in Chikwawa district.

3 Food security, equated with availability of maize, is the main electoral battleground in Malawi. This was the basis for the adoption of the input subsidy programme which does not yet have an exit strategy.

4 Focus Group Discussion with a mixed group of men and women farmers at Mnesa village in Mulanje district.

5 Focus Group Discussion with a mixed group of men and women farmers at Mpasu village in Chikwawa district.

6 Sentiment by a farmer from Mphampha village in Chikwawa district and widely shared by farmers represented at the learning event. 


\section{References}

Araujo, M.; Acosta, A.; Linan, A. and Saiegh, S. (2004) Political Institutions, Policy Making Policy Outcomes in Ecuador, Latin American Research Network, Inter-American Development Bank Chinsinga, B. (2008) 'Exploring the Politics of Land Reforms in Malawi: A Case Study of Community Based Rural Land Development Programme', IPPG Discussion Paper Series 20, University of Manchester, UK

Chinsinga, B. (2007) 'Reclaiming Policy Space: Lessons from Malawi's Fertilizer Subsidy Programme', paper presented at the World Development Report Workshop, Institute of Development Studies, 21-24 January

Clayton, H. and Culshaw, F. (2009) Science into Policy: Taking Part in the Process, London: Natural Environment Research Council

Dorward, A. and Chirwa, E. (2009) 'The Agricultural Input Subsidy Programme 2005 to 2008: Achievements and Challenges' (unpublished)

Government of Malawi (GoM) (1990) Crop Production Policy, Lilongwe, Malawi: Ministry of Agriculture

IDS (2006) Understanding Policy Processes; A Review of IDS Research on the Environment, Brighton: Knowledge, Technology and Society Team, Institute of Development Studies

Joshua, M.K.; Ngongondo, C.; Chipeta, L. and Ndau, S. (2008) 'Strengthening Local Agricultural Innovation Systems in Tanzania and Malawi to Adapt to the Challenges and
Opportunities Arising from Climate Change and Vulnerability', Situation Analysis, University of Malawi, Zomba: Chancellor College

Joshua, M.; Ngongondo, C.; Chipeta, L. and Ndau, S. (2010) Annual Project Progress Report, University of Malawi: Zomba Chancellor College

Keeley, J. and Scoones, I. (2003) Understanding Environmental Policy Processes: Cases from Africa, London: Earthscan/James \& James

Leftwich, A. (2007) 'The Political Approach to Institutional Formation, Maintenance and Change: A Literature Review Essay', IPPG Discussion Paper Series 14, University of Manchester

Makoka, M. (2008) 'The Impact of Drought on Household Vulnerability: A Case Study of Rural Malawi', paper presented at the 2008 United Nations University Summer Academy on Environmental Change, Migration and Social Vulnerability, 22-23 October

Smale, M. and Jayne, T. (2003) 'Maize in Eastern and Southern Africa: Seeds of Success in Retrospect', EPTD Discussion Paper 97, Washington DC: International Food Policy Research Institute

Synder, W. (2005) 'The Limitations and Successes of Sustainable Agriculture', unpublished MA thesis, University of Winnipeg, USA

World Bank (2010) Social Dimensions of Climate Change: Equity and Vulnerability in a Warming World, Washington DC: World Bank 